\title{
Postural changes in plasma renin activity and responses to vasoactive drugs in a case of Shy-Drager syndrome
}

\author{
C. J. MATHiAS, W. B. MATTHEWS, AND J. M. K. SPALDING 1 \\ From the Department of Neurology, Oxford Hospitals, Oxford, and National Spinal Injuries Centre, \\ Stoke Mandeville Hospital, Aylesbury
}

SUMMARY A male aged 47 years with gross autonomic insufficiency as part of the Shy-Drager syndrome is described. He did not sweat normally when warmed, and his circulatory responses to mental arithmetic, the Valsalva manoeuvre, and head-up tilt were abnormal indicating severe sympathetic failure. During head-up tilt there was a rise in plasma renin activity and plasma aldosterone. It is argued that plasma renin activity is not dependent on sympathetic nervous activity and may be mediated by renal baroreceptors. These rises may help sustain the blood pressure in such patients during repeated head-up tilts. Infusions of L-noradrenaline and angiotensin produced greater hypertension, and injections of isoprenaline greater hypotension than in controls. Although it is difficult to exclude the possibility that one factor in this may be hypersensitivity of receptors in blood vesseh walls, the principal factor is likely to be the absence of those baroreflexes of which the efferent pathways are in the sympathetic nervous system.

Orthostatic hypotension is a disabling manifestation of autonomic insufficiency, and is primarily due to the inability reflexly to increase sympathetic nervous activity on assuming the erect posture (Johnson and Spalding, 1974). It is suggested that the reninangiotensin system plays a compensatory role, but there is dispute whether plasma renin activity rises when patients with the Shy-Drager syndrome are tilted head-up. Furthermore, vasoactive drugs have been used to overcome the hypotension, but the responses in these patients to such drugs have not been fully compared with those in control subjects. We have therefore investigated a patient with the ShyDrager syndrome to elucidate his cardiovascular and hormonal responses to head-tilt and his cardiovascular responses to various vasoactive drugs.

\section{Methods}

The patient was a 47 year old man whose major complaints were impotence for eight years, frequency of micturition and nocturnal incontinence for five years,

${ }^{1}$ Address for correspondence: Dr J. M. K. Spalding, Department of Neurology, Radcliffe Infirmary, Oxford.

Accepted 27 August 1976 and shortness of breath and fainting on exertion an on standing for three years. There was progressive worsening of these symptoms over the few months before admission. For the last year he also had increasing 'lack of balance' and slurring of speech, especially at night, and difficulty in writing. He complained of fatigue and lethargy for six months and had been constipated for many years. He had attacks of 'sighs' which were like an exaggerated yawn. and had also had disturbed noisy breathing at night for the past four years. There was no family history of similar disease. He had also, for many years, had symptoms of a duodenal ulcer. The year before admission to the Churchill Hospital, Oxford, he had a haematemesis. Gastroscopy was performed elsewhere and during this he needed resuscitation and a tracheostomy. An emergency gastrectomy was performed because of a duodenal ulcer. He developed a cardiac arrest five weeks postoperatively, and then deep vein thrombosis for which he was treated with anticoagulants for two months. He continued to experience heartburn after meals.

On examination, blood pressure was $150 / 100$ $\mathrm{mmHg}$ while he was supine, $90 / 70 \mathrm{mmHg}$ while he was standing. There was no evidence of a primary cardiac disorder. There was mild cerebellar ataxia of 
all limbs and there were no other neurological abnormalities outside the autonomic nervous system. Blood counts and routine biochemical investigations were normal. A provisional diagnosis of autonomic insufficiency as part of the Shy-Drager syndrome (multiple system atrophy) was made (Shy and Drager, 1960; Bannister and Oppenheimer, 1972).

Further investigations of autonomic function were made. The patient gave his informed consent after the nature and implications of the procedures were fully explained. Drugs known to affect the autonomic nervous system were withdrawn for three days before the following investigations.

\section{INVESTIGATIONS}

Sweat test

Rectal temperature was raised by $1 \frac{1}{2}^{\circ} \mathrm{c}$ with a heat cradle and sweating assessed with starch-iodine paper.

\section{Cardiovascular responses to various stimuli}

Arterial blood pressure was measured by intraarterial catheter, heart rate derived from the arterial signal (using methods previously described (Mathias et al., 1975)), and the electrocardiograph was recorded intermittently during:

1. Mental arithmetic

2. Valsalva manoeuvre The patient raised intrathoracic pressure by blowing against the mercury column of a sphygmomanometer. An electromanometer was attached to the connecting tube so that airway pressure was recorded continuously.

3. Head-up tilt The patient was tilted on an electrical tilting bed. Plasma renin activity (by a modification of the method of Boyd et al., 1969 (Peart, 1976, unpublished)), plasma aldosterone (by the method of Mayes et al., 1970), plasma electrolytes, serum protein concentration, and the haematocrit were also measured before, during, and after head-up tilt. Head-up tilt was maintained for 30 minutes although the degree of tilt was reduced after 10 minutes as the patient felt faint. Blood was taken at intervals of 15 minutes during rest, after 10 , 20 , and 30 minutes of head-up tilt, and 15 and 30 minutes after return to the horizontal.

4. Administration of vasoactive drugs L-noradrenaline solution (Levophed, Winthrop Laboratories), at infusion rates of $0.6,2.3,4.6$, and 9.2 $\mu \mathrm{g} / \mathrm{min}$, was administered for five minutes each through a forearm vein using previously described methods (Mathias et al., 1976). The patient's responses were compared with those in six normal subjects studied under similar conditions, except that blood pressure was measured by sphygmomanometer and heart rate calculated from the electrocardiograph. Angiotensin amide (Hypertensin-Ciba)
$0.5 \mu \mathrm{g} / \mathrm{min}$ was infused intravenously for five minutes. Isoprenaline (Isoprenaline, Macarthys Ltd), in doses of $0.25,0.5$, and $0.75 \mu \mathrm{g}$, was injected intravenously with an interval of about five minutes between each injection. The patient's responses were compared with those in three paraplegic patients studied as controls under identical conditions. The paraplegics had lesions below T12/L1 cord segment, and therefore had an almost intact sympathetic nervous system.

\section{Results}

\section{SWEAT TEST}

There was heavy sweating on the palms, face, and axillae, minimal sweating on the chest and upper arms, and no sweating on the lower half of the upper arms and forearms or on the trunk below the waist and on the lower limbs. (Axillary sweating is largely independent of nerve supply (Johnson and Spalding, 1974).)

\section{RESPONSES TO CARDIOVASCULAR STIMULI \\ Mental arithmetic}

This did not change blood pressure or heart rate.

\section{Valsalva manoeuvre}

This manoeuvre resulted in abnormal cardiovascular responses which were similar to the 'blocked' responses characteristic of patients with autonomic insufficiency (Johnson and Spalding, 1974).

\section{Head-up tilt}

Tilt to $30^{\circ}$ caused a marked fall in systolic and diastolic blood pressure and rise in heart rate (Fig. 1). The patient felt faint but insisted that he could tolerate the degree of tilt. After 10 minutes the degree of tilt was reduced to $25^{\circ}$, at which level he was maintained for the next 20 minutes. After return to the horizontal there was no blood pressure overshoot, as is often seen in tetraplegic patients with cervical spinal cord transection (Corbett et al., 1971). Plasma renin activity at rest was within the resting range for normal supine subjects $\left(0-540 \mathrm{pg} \mathrm{h}^{-1} \mathrm{ml}^{-1}\right)$, and rose during head-up tilt (Fig. 1), the maximum rise occurring after 20 minutes. The levels fell towards the baseline after return to the horizontal. Resting plasma aldosterone levels were below the normal range of $8-10 \mathrm{ng} / 100 \mathrm{ml}$ and rose during head-up tilt. The rise, however, was later than the rise in plasma renin activity. There was no change in plasma electrolytes, serum protein concentration, or the haematocrit during or after head-up tilt.

Administration of vasoactive drugs

Intravenous infusion of L-noradrenaline caused a 

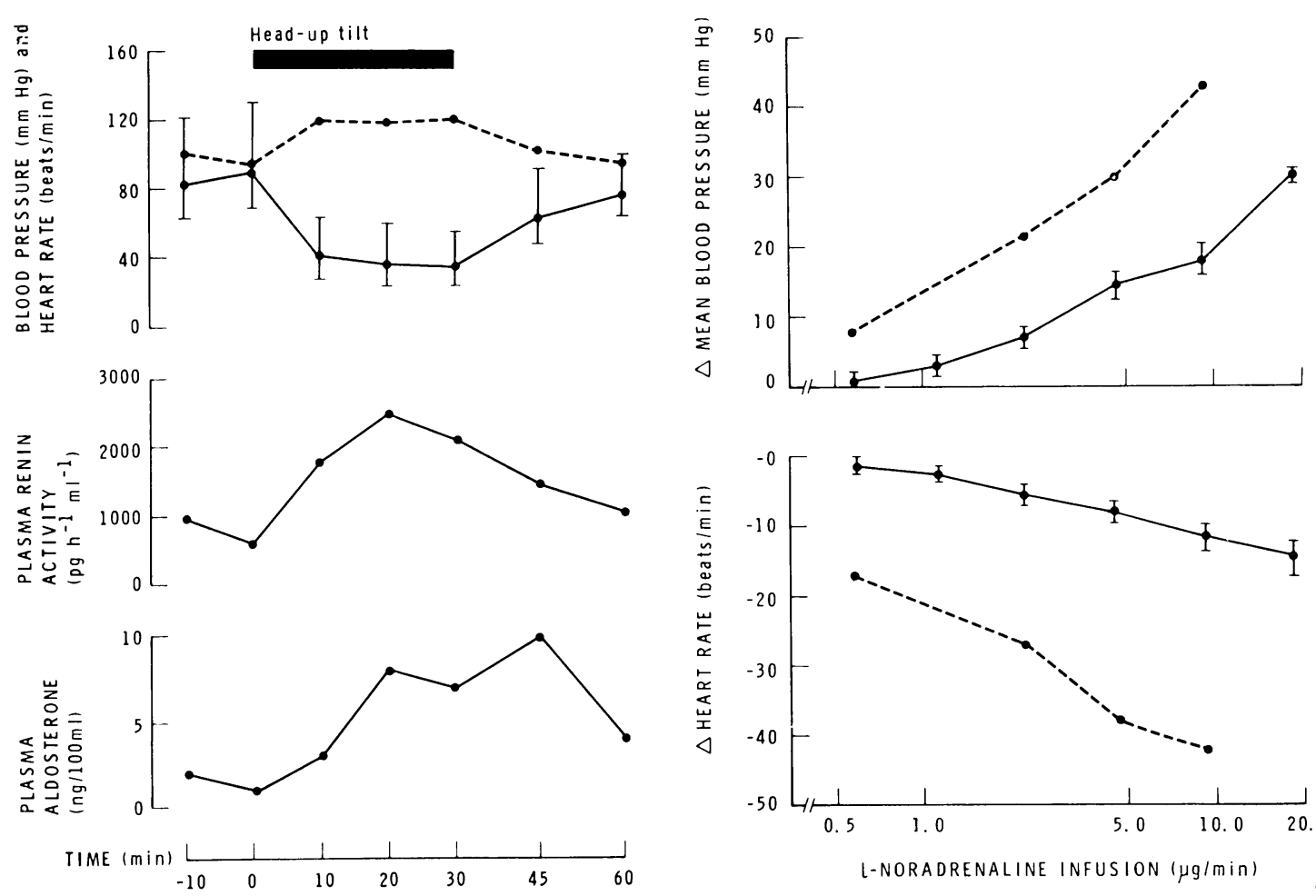

Fig. 1 Blood pressure (systolic, mean, diastolic) heart rate, plasma renin activity and plasma aldosterone in the patient with the Shy-Drager syndrome before (-10 and 0 min), during $(10,20$, and $30 \mathrm{~min}$ ), and after (45 and $60 \mathrm{~min}$ ) head-up tilt. - Mean blood pressure. --- Heart rate.

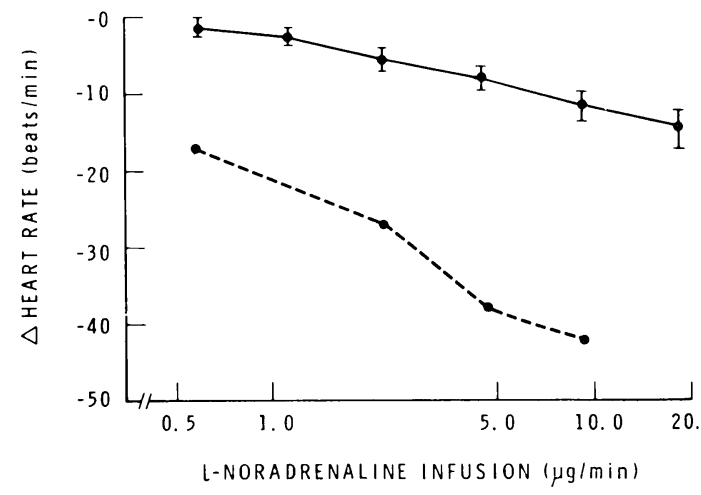

Fig. 2 Average change $(\triangle)$ in mean blood pressure and hear: rate during different dose infusion rates of L-noradrenaline in the patient with the Shy-Drager syndrome (---) and in six normal subjects (-). The bars indicate the $S E M+$.

and Drager, 1960; Bannister and Oppenheimer, 1972). The responses to the sweat test, mental arithmarked rise in blood pressure and a concomitant fall in heart rate which were greater than in the normal subjects (Fig. 2). Intravenous infusion of $0.5 \mu \mathrm{g} / \mathrm{min}$ angiotensin raised blood pressure from 110/65 (mean 80 ) $\mathrm{mmHg}$ to $180 / 85$ (mean 117) $\mathrm{mmHg}$, a mean rise of $37 \mathrm{mmHg}$. This response was greater than in normal subjects in whom $3.6 \mu \mathrm{g} / \mathrm{min}$ angiotensin are needed to raise mean blood pressure by $30-40 \mathrm{mmHg}$ (Brod et al., 1969). Heart rate fell from 90 to 62 beats/ min. Intravenous injection of isoprenaline resulted in a marked fall in blood pressure and rise in heart rate (Fig. 3). These responses were greater than in the three paraplegic patients who were studied as controls (Fig. 4).

\section{Discussion}

In this patient the history, the clinical features of autonomic involvement, and the cerebellar signs suggested a clinical diagnosis of autonomic insufficiency as part of the Shy-Drager syndrome (Shy metic, and the Valsalva manoeuvre indicated gross autonomic insufficiency (Johnson and Spalding, 1974), with the lesion in the sympathetic efferent pathways, probably from degeneration of cells in the intermediolateral column of the thoracic spinal cord, where sympathetic preganglionic cell bodies are situated (Johnson et al., 1966; Bannister and Oppenheimer, 1972). The afferent part of the baroreflex arc and the efferent fibres in the vagus nerve were active, as the heart rate varied inversely with blood pressure (Figs 1-4). The past history of cardiac arrest was also suggestive of unopposed cardiac vagal activity (Frankel et al., 1975; Welply et al., 1975).

The profound orthostatic hypotension in our patient was indicative of his inability reflexly to increase sympathetic nervous activity. In tetraplegics with cervical spinal cord transection, head-up tilt may cause a similar fall in blood pressure with a marked o rise in plasma renin activity (Mathias et al., 1975), or $N$ in plasma renin concentration (Johnson et al., 1971; N 

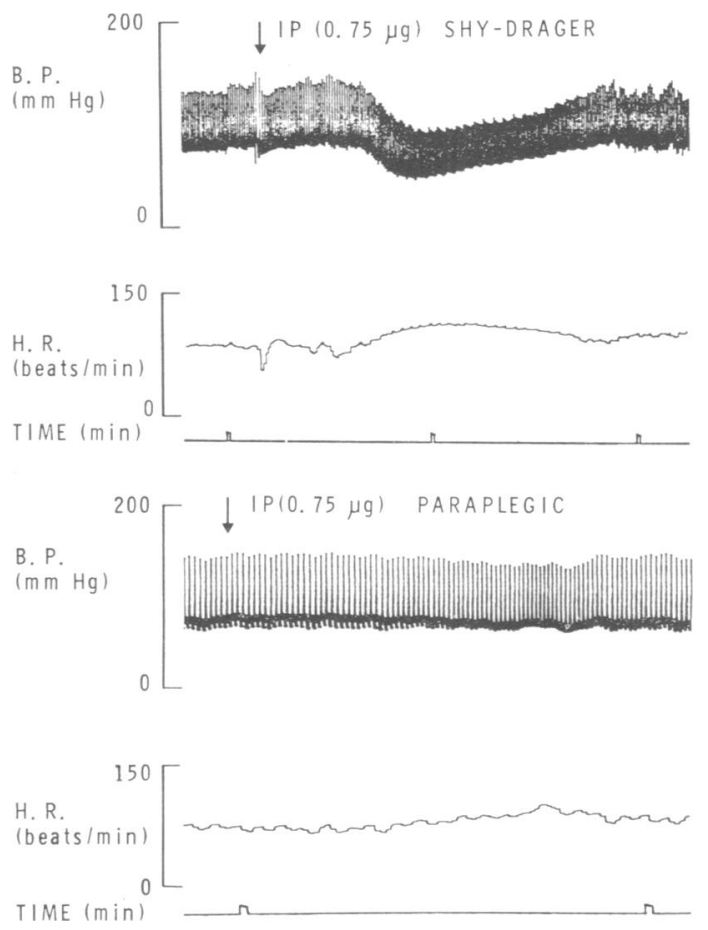

Fig. 3 Blood pressure (BP) and heart rate $(H R)$ in the patient with the Shy-Drager syndrome (upper record) and in a paraplegic patient with an L3 lesion (lower record) before, during, and after an intravenous injection of $0.75 \mu \mathrm{g}$ of isoprenaline (IP). The time scale differs in the lower record.

Johnson and Park, 1973). There is conflict, however, on whether plasma renin activity levels change during head-up tilt in patients with autonomic insufficiency due to lesions at other sites (Mathias et al., 1975). In our patient, head-up tilt caused a marked rise in plasma renin activity and a later rise in plasma aldosterone. If the lesion in this patient affected preganglionic sympathetic nerves it is unlikely that postganglionic nerves were reflexly active during the fall in blood pressure. This suggests that the release of renin is not dependent on sympathetic activity and may be mediated by a renal baroreceptor. The rise in plasma aldosterone may be secondary to the rise in plasma renin activity (Laragh et al., 1960), although an alteration in splanchnic blood flow and a subsequent effect upon metabolism should be considered (Davis, 1972). The renin-angiotensin system influences vascular tone and is capable of contributing to the support of the blood pressure in animals deprived of neurovascular reflexes (Brough et al., 1975). It may be that this system, together with aldosterone and its effect on plasma volume, may also
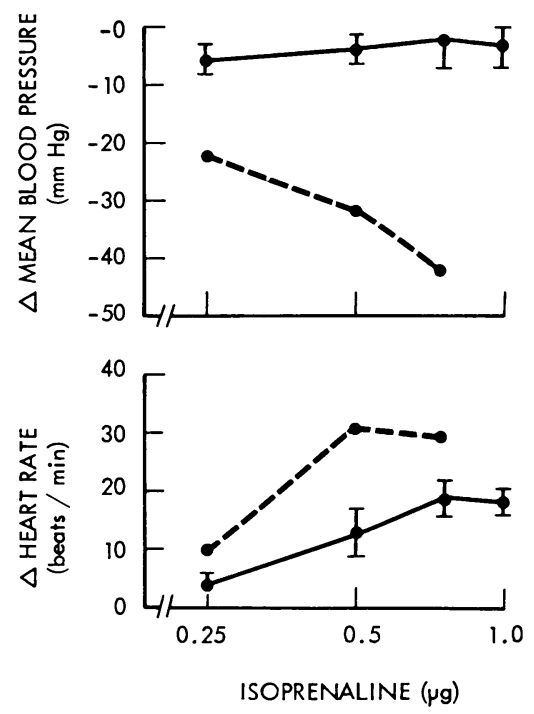

Fig. 4 Average change $(\triangle)$ in mean blood pressure and heart rate during intravenous bolus injections of isoprenaline in the patients with the Shy-Drager syndrome (----) and in three paraplegic patients with lesions below T12/L1 cord segment and an almost intact sympathetic nervous system (-). The bars indicate the $S E M+$.

contribute to blood pressure support in patients with autonomic insufficiency. These hormonal changes during head-up tilt may explain why patients with autonomic insufficiency have less orthostatic hypotension after repeated head-up tilts (Johnson et al., 1969) and may account for the benefit in these patients of the head-up posture at night (Bannister et al., 1969).

During infusion of noradrenaline the rise in blood pressure in our patient was greater than in normal subjects (Fig. 2). An enhanced response to noradrenaline does not necessarily indicate postganglionic sympathetic denervation as has been suggested by some workers (Barnett and Wagner, 1958; Razavi et al., 1960; Hohl et al., 1965), because it also occurs in tetraplegic patients who have intact sympathetic pathways in the spinal cord and its outflow below the level of the cervical lesion (Mathias et al., 1976). One factor accounting for the enhanced response in this patient may, as in tetraplegics, be hypersensitivity of adrenergic receptors in blood vessel walls. In our patient, however, the pressor response to infused angiotensin was also greater than in normal subjects, and this is consistent with previous observations in patients with autonomic failure (Hohl et al., 1965; Martin et al., 1968; Bannister et al., 1969). Pressor reactivity to infused angiotensin may be influenced 
by plasma renin and angiotensin levels, as a reduced pressor response has been reported in some subjects with raised levels (Weidmann et al., 1968; Lubash et al., 1971; Chinn and Dusterdieck, 1972). In our patient, however, resting plasma renin activity was normal and there appeared to be no reason for blood vessels to be abnormally sensitive to angiotensin. It is probable, therefore, that the increased pressor response both to noradrenaline and to angiotensin was due to impairment of baroreflexes as the brain could no longer control the sympathetic outflow. Because of this exaggerated response a posturally induced rise in circulating angiotensin may have a greater effect on blood pressure in patients with Shy-Drager syndrome than in normal subjects.

Isoprenaline injections in our patient caused a profound fall in blood pressure and an increase in heart rate. These responses were greater than in the paraplegic patients with an almost intact sympathetic nervous system (Fig. 4). An exaggerated response to sublingual isoprenaline has also been reported in a patient with idiopathic orthostatic hypotension (Barnett, 1968). Isoprenaline acts on $\beta-1$ adrenergic receptors and increases heart rate, and on $\beta-2$ adrenergic receptors and causes vasodilatation. It is likely that in our patient the vasodilatation was not accompanied by a reflex increase in sympathetic nervous vasoconstrictor activity, as would normally occur, and it is probable that this absence caused the marked hypotension. The increase in heart rate may be due to both $\beta$-1 receptor stimulation and a baroreceptor-induced effect through the vagus.

Our patient therefore had an exaggerated response to vasoactive drugs of differing pharmacological properties. While it is difficult to exclude the possibility that increased receptor sensitivity may play a part in these responses, it is more likely that they were due to the absence of those baroreflexes which involve sympathetic efferent pathways.

We are grateful to Professor W. S. Peart, Dr J. J. Walsh, and Dr H. L. Frankel for facilities and advice, the Lawson Tait Medical and Scientific Research Trust for support, and Dr S. Shorvon and Dr N. Hyman for assistance. We thank Mrs Jennifer Dulieu for the renin assays and Mr G. A. Wilson for the aldosterone measurements. The studies were performed when C. J. M. was a Rhodes Scholar at Oxford University. C. J. M. is presently a Research Fellow of the National Spinal Injuries Centre.

\section{References}

Bannister, R., Ardill, L., and Fentem, P. (1969). An assessment of various methods of treatment of idiopathic orthostatic hypotension. Quarterly Journal of Medicine, 38, 377-395.
Bannister, R., and Oppenheimer, D. R. (1972). Degenerative diseases of the nervous system associated with autonomic failure. Brain, 95, 457-474.

Barnett, A. J. (1968). Idiopathic orthostatic hypotension: a pharmacological study of the action of sympatho- 0 mimetic drugs. Medical Journal of Australia, 1, 213-216.

Barnett, A. J., and Wagner, G. R. (1958). Severe orthostatic hypotension: Case report and description of response to sympatheticomimetic drugs. American. Heart Journal, 56, 412-424.

Boyd, G. W., Fitz, A. E., Adamson, A. R., and Peart, W. S. (1969). Radioimmunoassay determination of 0 plasma-renin activity. Lancet, 1, 213-218.

Brod, J., Hejl, Z., Hornych, A., Jirka, J., Slechta, V., and $\overline{\bar{\sigma}}$ Burianova, B. (1969). Comparison of haemodynamic $\Phi$ effects of equipressor doses of intravenous angiotensin 2 and noradrenaline in man. Clinical Science, 36, 161-172. ळ)

Brough, J. R., Royce, B., Allen, W., Cowley, J. R., and $\vec{\circ}$ Guyton, A. C. (1975). Quantitative analysis of the acute response to haemorrhage of the renin-angio- $\vec{\omega}$ tensin-vasoconstrictor feedback loop in areflexic dogs. Cardiovascular Research, 9, 722-733.

Chinn, R. H., and Dusterdieck, G. (1972). The response of blood pressure to infusion of angiotensin II: Relation $\vec{f}$ to plasma concentrations of renin and angiotensin II. iv Clinical Science, 42, 489-504.

Corbett, J. L., Frankel, H. L., and Harris, P. J. (1971 Cardiovascular responses to tilting in tetraplegic man Journal of Physiology (Lond.), 215, 411-431.

Davis, J. O. (1972). Are there unidentified factors in the control of aldosterone section? New England Journal of Medicine, 286, 100-101.

Frankel, H. L, Mathias, C. J., and Spalding, J. M. K (1975). Mechanisms of reflex cardiac arrest in tetre plegic patients. Lancet, 2, 1183-1185.

Hohl, R. E., Frame, B., and Schatz, I. J. (1965). The Shy-Drager variant of idiopathic orthostatic hypotension. American Journal of Medicine, 39, 134-141.

Johnson, R. H., Lee, G. de J., Oppenheimer, D. R., and Spalding, J. M. K. (1966). Autonomic failure with orthostatic hypotension due to intermediolateral column degeneration. Quarterly Journal of Medicine, 35, 276-292.

Johnson, R. H., and Park, D. M. (1973). Effect of change of posture on blood pressure and plasma renin concentration in men with spinal transections. Clinical Science, 44, 539-546.

Johnson, R. H., Park, D., and Frankel, H. L. (1971). Orthostatic hypotension and the renin-angiotensin system in paraplegia. Paraplegia, 9, 146-152.

Johnson, R. H., Smith, A. C., and Spalding, J. M. K. (1969). Blood pressure response to standing and to Valsalva's manoeuvre: Independence of the two mechanisms in neurological diseases including cervical cord lesions. Clinical Science, 36, 77-86.

Johnson, R. H., and Spalding, J. M. K. (1974), Disorders of the Autonomic Nervous System. Blackwell: Oxford.

Laragh, J. H., Angers, M., Kelly, W. G., and Lieberman, S. (1960). Hypotensive agents and pressor substances. Journal of the American Medical Association, 174, 234-240.

Lubash, G. D., Muiesan, G. E., Alicandri, C. L., Gar- 
finkel, D. J., Siekierski, E. C., and McGonnaughey, C. K. (1971). Plasma angiotensin, serum angiotensinase activity and blood pressure response during angiotensin II amide infusions in normal volunteers. Experientia (Basel), 27, 68-69.

Martin, J. B., Travis, R. H., and van den Noort, S. (1968). Centrally mediated orthostatic hypotension. Archives of Neurology (Chic.), 19, 163-173.

Mathias, C. J., Christensen, N. J., Corbett, J. L., Frankel, H. L., Goodwin, T. J., and Peart, W. S. (1975). Plasma catecholamines, plasma renin activity and plasma aldosterone in tetraplegic man, horizontal and tilted. Clinical Science and Molecular Medicine, 49, 291-299.

Mathias, C. J., Frankel, H. L., Christensen, N. J., and Spalding, J. M. K. (1976). Enhanced pressor response to noradrenaline in patients with cervical spinal cord transection. Brain, 99, 757-770.
Mayes, D., Furuyama, S., Kem, D. G., and Nugent, C. A. (1970). A radioimmunoassay for plasma aldosterone. Journal of Clinical Endocrinology, 30, 682-685.

Razavi, M., Nelson, A. R., and Picchi, J. (1960). Postural hypotension associated with anhidrosis and unchanging pulse. Archives of Internal Medicine, 106, 657-662.

Shy, G. M., and Drager, G. A. (1960). A neurological syndrome associated with orthostatic hypotension. Archives of Neurology (Chic.), 2, 511-527.

Weidmann, P., Endres, P., and Siegethaler, W. (1968). Plasma renin activity and angiotensin pressor dose in hypertension: Correlation and diagnostic implications. British Medical Journal, 3, 154-156.

Welply, N., Mathias, C. J., and Frankel, H. L. (1975). Circulatory reflexes in tetraplegics during artificial ventilation and general anaesthesia. Paraplegia, 13, 172-182. 